\title{
Article \\ Effects of Tea Polyphenol Treatments on the Quality and Microbiota of Crisp Grass Carp Fillets during Storage at $4{ }^{\circ} \mathrm{C}$
}

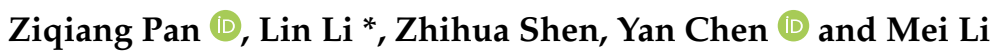 \\ College of Materials and Food, Zhongshan Institute, University of Electronic Science and Technology of China, \\ Zhongshan 528402, China; ziqiang_pan@163.com (Z.P.); shenzhihua123@126.com (Z.S.); \\ Chenyanmail2012@gmail.com (Y.C.); 1 2m2570@163.com (M.L.) \\ * Correspondence: lilinxiaoman@163.com; Tel.: +86-760-88325742; Fax: +86-760-88328561
}

check for updates

Citation: Pan, Z.; Li, L.; Shen, Z.;

Chen, Y.; Li, M. Effects of Tea

Polyphenol Treatments on the Quality and Microbiota of Crisp Grass Carp Fillets during Storage at $4{ }^{\circ} \mathrm{C}$. Appl. Sci. 2021, 11, 4370. https://doi.org/ 10.3390/app11104370

Academic Editor: Claudio Medana

Received: 8 April 2021

Accepted: 1 May 2021

Published: 12 May 2021

Publisher's Note: MDPI stays neutral with regard to jurisdictional claims in published maps and institutional affiliations.

Copyright: (c) 2021 by the authors. Licensee MDPI, Basel, Switzerland. This article is an open access article distributed under the terms and conditions of the Creative Commons Attribution (CC BY) license (https:// creativecommons.org/licenses/by/ $4.0 /)$.
Abstract: We investigated the effects of tea polyphenol treatments on the quality and microbiota of crisp grass carp fillets during cold storage at $4{ }^{\circ} \mathrm{C}$. Changes in the total viable count (TVC) and total volatile base nitrogen (TVB-N) of fillets were measured. The microbiota of the crisp grass carp was analyzed using high-throughput sequencing technique. The results indicated that tea polyphenol treatments inhibited bacterial growth and reduced TVB-N values of fish fillets, and subsequently extended their shelf life by 6 days. The high-throughput sequencing result showed that Pseudomonas was the most abundant bacteria in tea polyphenol-treated fish fillets at the end of shelf life, while Pseudomonas and Aeromonas were the most abundant bacteria in control samples. These findings suggested that tea polyphenol treatments could be used in future to extend the shelf life of crisp grass carp fillets and alter the bacterial communities responsible for spoiling fish.

Keywords: crisp grass carp; tea polyphenols; Pseudomonas; Aeromonas; spoilage

\section{Introduction}

Food spoilage during storage is a global problem as $25 \%$ of the world's gross primary agricultural and fishery products are wasted through chemical deterioration and microbial spoilage every year [1]. Enzymatic autolysis, oxidation, and microbial growth are the three main mechanisms leading to the spoilage of fish. To extend the shelf life of fish, different types of preservation methods, such as drying, smoking, brining, fermentation, canning, freezing, and chilling, are used. Of these methods, low-temperature storage and application of chemicals for controlling water activity, enzymatic, oxidative, and microbial spoilage remain the most common preservation techniques in the industry [2,3]. However, increase in environmental awareness has increased the demand for natural and non-toxic biological preservatives for usage in food processing, storage, and transportation. Tea polyphenols extracted from green tea are biological preservatives that contain polyphenolic compounds, such as catechins, flavanols, and phenolic acids with antibacterial and antioxidative activities $[4,5]$. Tea polyphenols have previously been used to maintain the quality and extend the shelf life of fish, such as silver carp [6,7], crucian carp [8], large yellow croaker [9], and weever [10]. To expand the range of their applications, it is necessary to explore the use of tea polyphenols on additional fish species.

Crisp grass carp (Ctenopharyngodon idella C. et V.), a widespread freshwater fish in China, has firm muscles and higher concentrations of crude proteins, fats, and amino acids, than the common grass carp (Ctenopharyngodon idella) [11]. In our previous study, Aeromonas and Pseudomonas were found to be the major microbial organisms in the air- and vacuum-packed crisp grass carp fillets responsible for spoilage during chilled storage [12] There have been no studies on the use of tea polyphenols to extend the shelf life of crisp grass carp during storage at $4{ }^{\circ} \mathrm{C}$. This study aimed to investigate the effects of a tea polyphenol dip treatment on the shelf life of crisp grass carp during cold storage at $4{ }^{\circ} \mathrm{C}$. 


\section{Materials and Methods}

\subsection{Preparations of the Fish Samples}

Crisp grass carp, with a weight of $5500 \pm 100 \mathrm{~g}$, were obtained from Zhongshan Yunongchan Group Corp. (Zhongshan, China). The production process of the fish fillets was as per our previous study [12]. The fillet size was about $5 \mathrm{~cm}$ long, $3 \mathrm{~cm}$ wide, and $0.5 \mathrm{~cm}$ thick, with a weight of $15 \pm 2 \mathrm{~g}$. The fillets were dipped in $0.2 \%(w / v)$ tea polyphenol (Shanghai Yantuo Biotechnology Co., LTD., China) solution $\left(4 \pm 1^{\circ} \mathrm{C}\right)$ for $30 \mathrm{~min}$ [10] and drained well. The fillets in the control group were dipped in distilled water $\left(4 \pm 1^{\circ} \mathrm{C}\right)$ for $30 \mathrm{~min}$ and drained well. The treated and control group samples, each approximately $500 \mathrm{~g}$, were packed in polyethylene bag sand stored at $4 \pm 1{ }^{\circ} \mathrm{C}$. Twenty-five grams of fish fillets were collected for the total viable counts (TVC) and total volatile base nitrogen (TVB-N) analyses after $0,1,2,3,4,6,8,10,12,14$, and 16 days of treatment, and the total microbial DNA was extracted after $0,3,6$, and 12 days.

\subsection{Bacteriological Analysis}

TVC of the crisp grass carp were determined as per the standards of the Association of Official Analytical Chemists [13]. Twenty-five grams of each fish fillet were aseptically weighed and homogenized with $225 \mathrm{~mL}$ of sterile peptone water $(0.1 \% \mathrm{w} / \mathrm{v}$ peptone and $0.9 \% w / v \mathrm{NaCl}$ ) for $2 \mathrm{~min}$ in a Stomacher 400 Laboratory Blender (AJ Steward Company Ltd., London, UK). The homogenized samples were serially diluted using $9 \mathrm{~mL}$ of sterile peptone water and subjected to bacteriological analysis. The TVC was determined by Aerobic Count Plates (3M Microbiology Products, St Paul, MN, USA), according to the manufacturer's instructions after incubation at $25^{\circ} \mathrm{C}$ for $48 \mathrm{~h}$.

\subsection{Determination of Total Volatile Basic Nitrogen}

TVB-N was determined, as per previously described method [14]. Briefly, in a $500 \mathrm{~mL}$ round bottom flask, $50 \mathrm{~mL}$ of the mixture from the bacteriological analysis was mixed with $200 \mathrm{~mL}$ of distilled water and distilled after the addition of $2 \mathrm{~g}$ of $\mathrm{MgO}$ and one drop of silicone to prevent foaming. The distillate was collected in a $250 \mathrm{~mL}$ flask containing $25 \mathrm{~mL}$ of $3 \%$ aqueous solution of boric acid, $0.04 \mathrm{~mL}$ of methyl red, and methylene blue mixed indicator. Next, $125 \mathrm{~mL}$ of the distillate was titrated with $0.1 \mathrm{~mol} \mathrm{~L}^{-1}$ hydrochloric acid solution and the TVB-N ( $\mu \mathrm{g} \mathrm{g}^{-1}$ ) of fish fillets was determined, according to the consumption of hydrochloric acid.

\subsection{S rRNA High-Throughput Sequencing Analysis}

Bacteria were collected from fish fillets (Section 2.1), as per our previously described method [12]. Bacterial DNA was extracted by using a Bacterial DNA Kit (Omega Bio-tek, Doraville, GA, USA) and sent to the Science Corporation of Gene (Guangzhou, China) for 16S rRNA high-throughput sequencing on an Illumina HiSeq2500 platform. The sequencing procedures and sequencing data analysis have previously been described in detail [12].

\subsection{Statistical Analysis}

Each treatment experiment was replicated twice, and each replicate was analyzed in triplicates. The data of TVC and TVB-N were analyzed by using SPSS software (Version 25.0). A generalized linear model (GLM) with Poisson error distribution was used to analyze the differences between treatments with respect to TVC and TVB-N (two-way ANOVA). Differences in the microbial populations between different treatment groups were compared using the Mann-Whitney test. Results with $p<0.05$ were considered statistically significant.

\section{Results and Discussion}

\subsection{Bacteriological Analysis}

Microbial activity is one of the main factors leading to the spoilage of preserved food with high moisture content. The total viable count (TVC) was used as an indicator of 
the quality of hygiene and the degree of spoilage; $7 \log \mathrm{CFU} \mathrm{g^{-1 }}$ is often used as the maximum level for fish sold for human consumption [15]. Changes in TVC for crisp grass carp during $4{ }^{\circ} \mathrm{C}$ storage are presented in Figure 1. The initial TVC of the fresh fish fillets was $4.08 \log$ CFU g ${ }^{-1}$. Our results showed that the microbial growth started immediately in the control fish fillets but had a lag phase of about 2 days in samples treated with tea polyphenols. During the chilled storage, the TVC values of the tea polyphenol-treated fish were lower than the controls at all time points $\left(1-2 \log \mathrm{CFU} \mathrm{g}^{-1}\right)$. After 6 days, the TVC in the control increased to $7.32 \log \mathrm{CFU} \mathrm{g}{ }^{-1}$ and reached the maximum limit of acceptable microbial count after 6 days, as reported in previous reports [16]. In contrast, the TVC value for the fish fillets treated with the tea polyphenols was $7.09 \log \mathrm{CFU} \mathrm{g}{ }^{-1}$ after 12 days (Figure 1). Our results showed that the tea polyphenols significantly inhibited the bacterial growth compared to the control groups $(p<0.05)$ and extended crisp grass carp shelf life by 6 days. The bacteriostatic effects of the tea polyphenols have been reported in previous studies [6-10]. In comparison, the shelf life of crisp grass carp treated with or without tea polyphenols was shorter than that of crucian carp. The main reason is that the initial TVC of crisp grass carp which was $4.08 \log \mathrm{CFU} \mathrm{g}{ }^{-1}$ was higher than that of crucian carp which was $2.84 \log \mathrm{CFU} \mathrm{g}^{-1}$ [8].

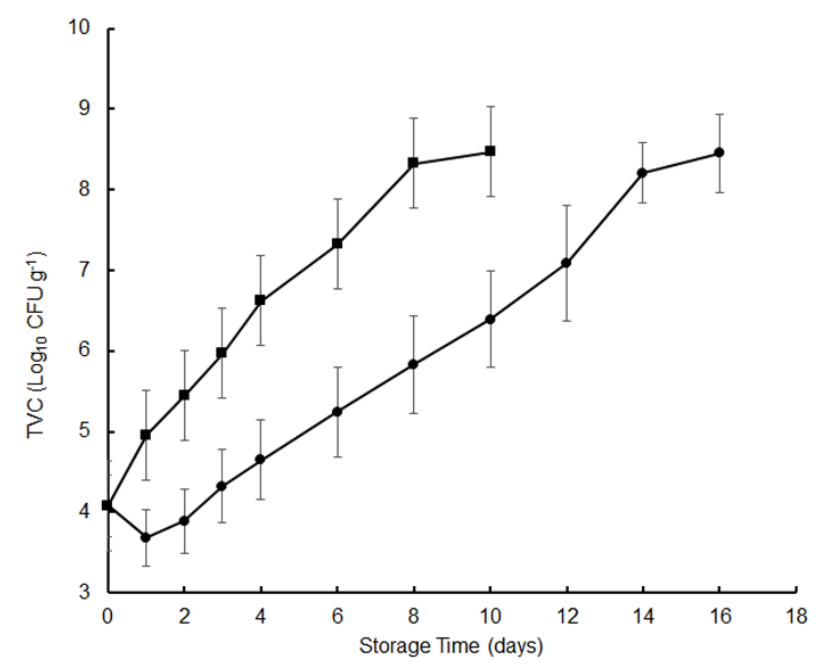

Figure 1. Changes in the total viable count (TVC) of crisp grass carp fillets during storage at $4{ }^{\circ} \mathrm{C}$. CFU, Colony-Forming Units. $\mathbf{\square}$, distilled water treatments; $\bullet$, tea polyphenol treatments.

\subsection{Total Volatile Basic Nitrogen (TVB-N) Analysis}

TVB-N measurement includes trimethylamine, dimethylamine, ammonia, and other volatile basic nitrogenous compounds, and is one of the most widely used indicators to determine the degree of fish spoilage caused by bacteria and autolytic enzymes $[8,17,18]$. In the present study, the initial TVB-N value of the fresh fish fillets was $84.3 \mu \mathrm{g} \mathrm{g}^{-1}$. The TVB-N value of the fillets treated with tea polyphenols decreased on the first day itself, presumably due to the antioxidative activities of the polyphenols. Subsequently, the TVB$\mathrm{N}$ values increased gradually in all samples during the chilled storage (Figure 2). The TVB-N value in the control group increased to $252.7 \pm 29.3 \mu \mathrm{g} \mathrm{g}^{-1}$ after 8 days, while in samples treated with the tea polyphenol, it increased to $172.6 \pm 12.3 \mu \mathrm{g} \mathrm{g}^{-1}$. Since TVB-N is produced mainly by bacterial decomposition of fish fillets, the higher TVC values observed in the control, as compared to the treated samples after 8 days of the cold storage, could account for the higher TVB-N values. The TVB-N value of the fillets treated with tea polyphenol was $258.4 \pm 14.6 \mathrm{\mu g} \mathrm{g}^{-1}$ after 16 days, which was lower than those of the control during the chilled storage period (Figure 2). Our results showed that the tea polyphenols application significantly reduced the TVB-N values of crisp grass carp during cold storage $(p<0.05)$; TVB-N results were consistent with the TVC results (Figure 1). Tea polyphenols dip could lead silver carp to either a rapid decrease of the bacterial population or decrease 
the ability of bacteria for oxidative deamination non-protein nitrogen compounds, or both [6]. Similarly, dipping crisp grass carp in tea polyphenols could effectively inhibited microbial growth, and TVB-N value level was significantly lower for the treated samples than for the control samples. The inhibitory effects of tea polyphenols on the TVB-N values have also been reported in silver carp [6], crucian carp [8], large yellow croaker [9], and weever [10]. When considering a TVB-N value level of $250 \mathrm{\mu g} \mathrm{g}^{-1}$ fresh fish as the acceptable limit proposed by Ojagh et al., [19], the shelf life of the control and the treated samples were about 8 and nearly 16 days, respectively. Although TVB-N is widely used as an indicator for fish deterioration, various authors have reported different acceptable values of TVB-N for different fish species, different treatments, and different processing conditions [6]. Therefore, the shelf life of the crisp grass carp during the chilled storage was determined from the TVC values observed in this study.

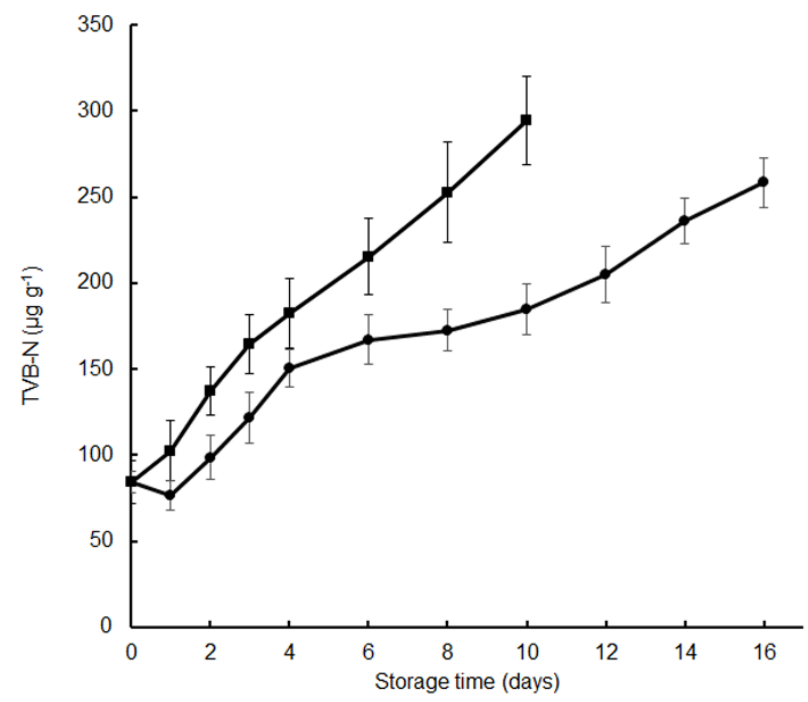

Figure 2. Changes in total volatile basic nitrogen (TVB-N) of crisp grass carp fillets during storage at $4{ }^{\circ} \mathrm{C}$. $\mathbf{\square}$, distilled water treatments; $\bullet$, tea polyphenol treatments.

\section{3. $16 S$ rRNA High-Throughput Sequencing Analysis}

The 16S rRNA V3-V4 regions were sequenced on the Illumina HiSeq 2500 platform, and the results are shown in Table 1. A total of 557,980 effective tags were generated from five samples, with an average of 111,596 tags per sample (range $=57,660-150,114$, $\mathrm{SD}=40,224)$. These sequences were grouped into 64,515 operational taxonomic units (OTUs) and assigned into 209 classified bacterial genera. The Shannon index and Simpson index of fresh fish fillets were 7.32 and 0.96 , respectively, which were the highest among all fish samples (Table 1). The highest diversity indices indicated that the bacterial diversity was most abundant in the fresh fish fillets; this was also manifested in the relative abundance of the bacterial phyla and genera (Figure 4). Compared with fresh fish fillets, the Shannon index and Simpson index of the control samples decreased to 6.03 and 0.80 , respectively, on day 3 (C3) of cold storage. The diversity index of the control samples on day 6 (C6) was similar to that on C3 (Table 1). The Shannon index and Simpson index of tea polyphenol-treated fillets reduced sharply to 3.05 and 0.40 on day 12 (TP12), respectively, but decreased slightly to 6.80 and 0.93 on day 6 (TP6), respectively. The reason for the decrease in the diversity of the control and treated samples could be due to the fact that some species of bacteria gradually adapt to the environment and become dominant during microbial growth responsible for spoilage. The results of the taxonomic assignment confirmed our hypothesis, with Aeromonas accounting for $50.1 \%$ in C3 samples and Pseudomonas accounting for $50.4 \%$ and $97 \%$ in C6 and TP12 samples, respectively (Figure 4). Diversity indices indicated that the bacterial diversity decreased as crisp grass carp spoiled; 
similar findings were reported earlier [7,12]. The higher diversity of TP6 samples than of C6 samples implied that tea polyphenol treatments delayed the growth of the dominant bacteria. This speculation was supported by the TVC results (Figure 1) and the abundance of the bacterial genera that accounted for not more than $21 \%$ (Figure 4 ).

Table 1. Crisp grass carp sample information, microbial diversity, and sequence analysis.

\begin{tabular}{ccccccc}
\hline Sample $^{*}$ & No. of Reads & No. of OTUs & Chao1 Index & Shannon Index & Simpson Index & No. of Genera \\
\hline D0 & 82,359 & 9915 & 53,904 & 7.32 & 6.96 & 76 \\
C3 & 150,114 & 18,824 & 126,204 & 6.05 & 0.80 & 31 \\
C6 & 144,592 & 18,146 & 132,612 & 6.80 & 0.86 & 73 \\
TP6 & 57,660 & 7586 & 46,409 & 3.05 & 0.40 & 11 \\
TP12 & 123,255 & 10,044 & 67,274 & 5.85 & 0.79 & 42 \\
Mean & 111,596 & 12,903 & 85,280 & \pm 1.66 & \pm 0.23 & \pm 29 \\
I SD & $\pm 40,224$ & \pm 5194 & $\pm 41,032$ & \pm 1 & \\
\hline
\end{tabular}

${ }^{*}$ D0 indicates fresh, crisp grass carp fillets prior to any treatment. C3 and C6 indicate the fillet samples that were treated with distilled water and stored for 3 and 6 days, respectively. TP6 and TP12 indicate the fillet samples that were treated with tea polyphenols and stored for 6 and 12 days, respectively.

Principal coordinate analysis of the bacterial communities was performed to evaluate the similarities in the bacterial communities during cold storage. Both the weighted (Figure 3a) and unweighted (Figure 3b) samples revealed that the bacterial communities of the fresh fish (D0) were significantly different from those of the spoiled fish (C6 and TP12) $(p<0.05)$, and these observations were in line with previous studies [7,12]. The bacterial communities in samples treated with the tea polyphenol and distilled water changed significantly during the storage period (TP6 and TP12, C3 and C6, $p<0.05$ ). However, the microbiome composition was strikingly similar between C3 and T6 (also C6 and T12), which implied delayed spoilage of fish treated with tea polyphenols. These findings were further confirmed by the results of the relative abundance of the bacterial genus (Figure $4 \mathrm{~b}$ ), which showed that the bacterial population were similar in composition but different in proportion.
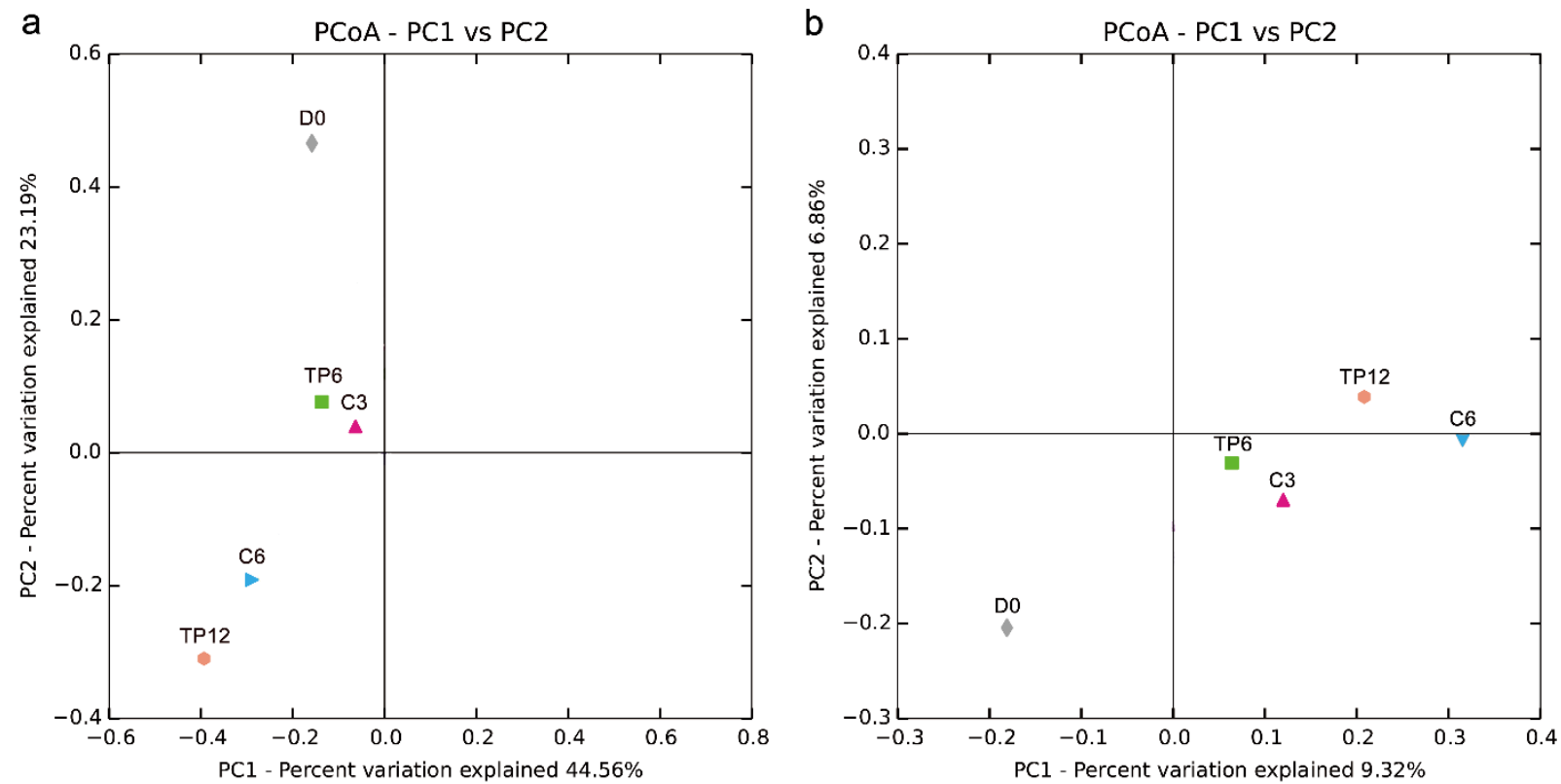

Figure 3. Principal coordinate analysis of the crisp grass carp fillet bacterial communities based on (a) weighted and (b) unweighted UniFrac metrics of samples during storage at $4{ }^{\circ} \mathrm{C}$. 
a

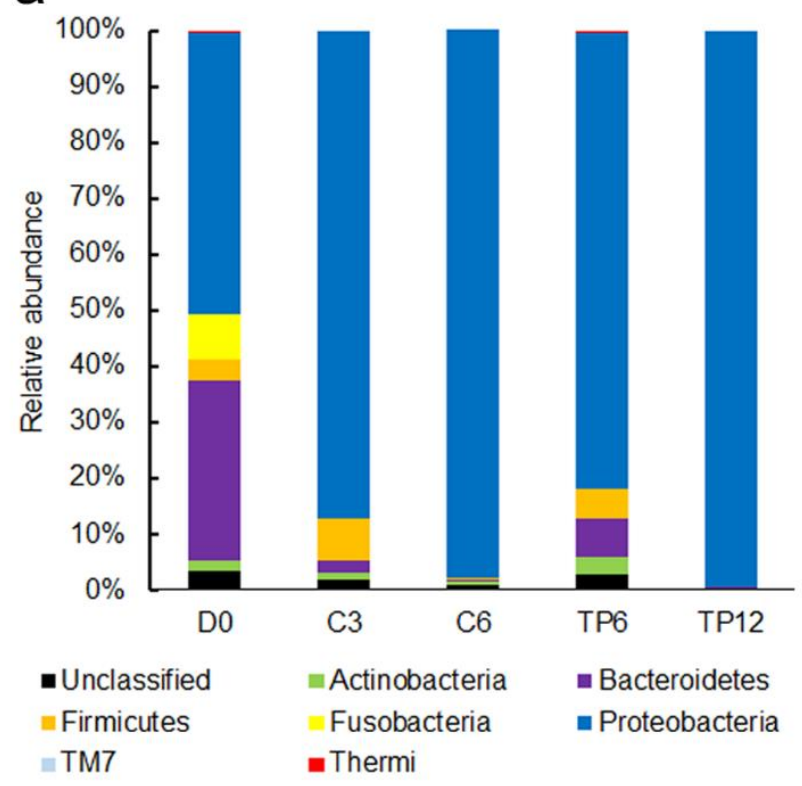

b

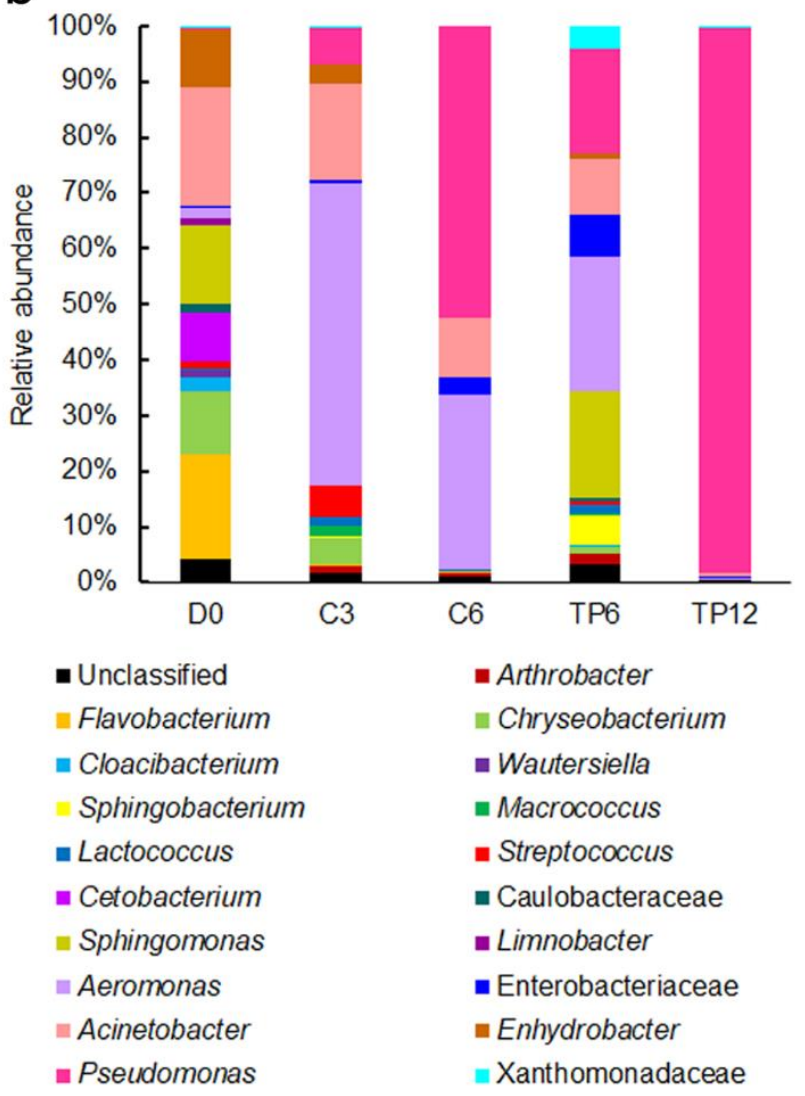

Figure 4. Relative abundance of the bacterial phyla (a) and genera (b) in crisp grass carp fillets during chilled storage at $4{ }^{\circ} \mathrm{C}$. Only genera $\geq 1 \%$ of the total relative abundance of the samples are shown.

Seven bacterial phyla were identified in the fresh fillets (D0), consisting of Actinobacteria, Bacteroidetes, Firmicutes, Fusobacteria, Proteobacteria, TM7, and Thermi (Figure 4a). In the fresh fillet, the predominant phyla were Proteobacteria and Bacteroidetes (accounting for $50.1 \%$ and $32.3 \%$ of the bacteria, respectively). By 6 th day, the Proteobacteria increased significantly to $97.8 \%$ in the fillet treated with distilled water, as compared to $99.3 \%$ in the fillet treated with tea polyphenols by the end of 12 days. In contrast, Bacteroidetes declined sharply to $0.4 \%$ in the fillet treated with distilled water and to $0.1 \%$ in fillet treated with the tea polyphenols; these findings are consistent with previously published studies [12]. Interestingly, the relative abundance of Fusobacteria, accounting for $8.1 \%$ of the bacteria in the fresh fillets, was higher in our study than that reported in previous studies, which disappeared by the end of the storage period [12].

The dynamics of the bacterial community (at the genus level) during the cold storage at $4{ }^{\circ} \mathrm{C}$, are displayed in Figure $4 \mathrm{~b}$. By the end of the cold storage, seventy six genera of bacteria were identified in the fresh fillets, which was significantly higher than the number of genera identified in the samples treated with tea polyphenols (21 genera) or distilled water (11 genera) (Table 1); the principal genera identified in samples included Acinetobacter, Flavobacterium, Sphingomonas, Chryseobacterium, Enhydrobacter, and Cetobacterium, constituting for $17.9,15.6,11.8,9.5,8.6$, and $7.5 \%$ of bacterial population in fresh fillets, respectively (Figure $4 \mathrm{~b}$ ). Acinetobacter commonly found in natural waters was the predominant bacteria not only in the crisp grass carp fillets of this study and those reported previously [12] but also in grass carp (Ctenopharyngodon idellus) [20], common carp (Cyprinus carpio) [21] and silver carp (Hypophthalmichthys molitrix) [7], suggesting that Acinetobacter could be the resident flora in this fish. After 3 days, this bacterial genus decreased slightly to $16.1 \%$ in the distilled water treated fillets during the $4{ }^{\circ} \mathrm{C}$ storage and declined to $10.3 \%$ after 6 days. 
In contrast, its abundance decreased significantly to $8.7 \%$ after 6 days in the fillet treated with tea polyphenols and then decreased sharply to $0.6 \%$ after 12 days. These results indicated tea polyphenols inhibited the growth of Acinetobacter, which was consistent with the results of Jia et al., [7]. The decrease in Acinetobacter during the storage period in this study indicated that this genus contributed negligibly to fillet spoilage. Similar results have been reported by previous reports $[12,20]$. In the distilled water treated fillets, Flavobacterium, Chryseobacterium, and Enhydrobacter reduced dramatically to $0.2,0.2$, and $0.1 \%$, respectively, while the other genera, Sphingomonas and Cetobacterium, disappeared after 6 days. These five genera disappeared in the fillet treated with tea polyphenols during the storage period, thereby indicating that these genera do not contribute to the spoilage of crisp grass carp. In the fresh crisp grass carp fillets, the bacterial community and its abundance were slightly different in comparison to those reported by a previous study [12]. For example, the bacterial communities included the genera Cetobacterium and Limnobacter, but did not include the genera Sphingobacterium and Macrococcus; this could be explained by the difference in capture times and locations.

Unlike the aforementioned microorganisms that are not related to the spoilage process, Pseudomonas and Aeromonas play an important role in the spoilage of crisp grass carp. The minor genus Pseudomonas in the fresh fillets increased rapidly and became dominant in tea polyphenol treated and distilled water treated samples by the end of their shelf life (from an initial $0.4 \%$ to $50.4 \%$ after 6 days for the distilled water treated fillets, and to $97.4 \%$ after 12 days for the tea polyphenol-treated fillets). This showed that Pseudomonas spp. are the main spoilage organisms responsible for the spoilage of crisp grass carp treated with tea polyphenols, in accordance with a previous study that identified species of this genus as the spoilage organisms of freshwater fish $[7,22]$. Compared to the increased abundance of Pseudomonas, the fluctuations of the abundance of Aeromonas were found to be of interest in the two treated samples during the storage period. In the distilled water treated fillets, the proportion of Aeromonas increased from $1.5 \%$ on day 0 to $50.1 \%$ on day 3 but declined to $30.3 \%$ after 6 days. In addition to Pseudomonas, Aeromonas was another major dominant bacterium in spoiled crisp grass carp treated with distilled water, and this was in agreement with the findings of previous studies [7,12]. Aeromonas species have also been reported to be the main spoilage organisms for many freshwater fish species $[7,20,21,23,24]$. These two genera had strong spoilage potential, which may be the reason why the value of TVB-N increased rapidly in the control samples. However, in the tea polyphenol-treated fillets, Aeromonas increased from an initial $1.5 \%$ on day 0 to $21.0 \%$ after 6 days but declined dramatically to just $0.2 \%$ after 12 days.

We found that Aeromonas and Pseudomonas accounted for $30.3 \%$ and $50.4 \%$ of the bacteria in non-treated fillets with a TVC value of $7.32 \log$ CFU g ${ }^{-1}$ on day 6 but accounted for only $21 \%$ and $16.2 \%$ in tea polyphenol-treated fillets with a TVC value of $5.24 \log \mathrm{CFU} \mathrm{g}^{-1}$ (Figures 1 and $4 \mathrm{~b}$ ). At the end of storage, the main spoilage bacteria of crisp grass carp fillets changed from Pseudomonas and Aeromonas to Pseudomonas in fillet treated with tea polyphenols. These results indicated that tea polyphenols could inhibit the growth of Aeromonas and Pseudomonas and alter the composition of microbiota in crisp grass carp fillets during chilled storage.

\section{Conclusions}

In the present study, $0.2 \%$ of tea polyphenols treatment could effectively inhibit the growth of bacteria and reduce the production of TVB-N, and extend the shelf-life of crisp grass carp for 6 days during cold storage at $4{ }^{\circ} \mathrm{C}$. The high-throughput sequencing results showed that fresh fish fillets had a more diverse bacterial population than spoiled fish. Pseudomonas was the most abundant bacteria accounting $97.4 \%$ in tea polyphenoltreated fillets at the end of shelf-life, while Pseudomonas and Aeromonas were the most abundant bacteria accounting for $50.4 \%$ and $30.3 \%$ in control samples. We suggested that tea polyphenols are capable of altering bacterial communities that grow at $4{ }^{\circ} \mathrm{C}$. These findings will help to improve the shelf life of these fish in cold storage by using tea polyphenols. 
Further studies are warranted to validate these findings before tea polyphenols can be considered at industrial levels for improved cold storage of crisp grass carp.

Author Contributions: Z.P. and L.L. contributed the central idea, analysed most of the data, and wrote the initial draft of the paper. The remaining authors contributed to refining the ideas, carrying out additional analyses and finalizing this paper. All authors have read and agreed to the published version of the manuscript.

Funding: This research was funded by the National Natural Science Foundation of China (grant number 31401565), Major projects in key fields of colleges and universities in Guangdong Province (2020ZDZX3027), Major public welfare projects in Zhongshan City (2018B1023 and 2019B2013), and Special innovation projects of Guangdong Universities (2020KTSCX184).

Institutional Review Board Statement: Not applicable.

Informed Consent Statement: Not applicable.

Data Availability Statement: Not applicable.

Acknowledgments: We thank Wenli Liu for his contribution to the statistical analysis of the study. This work was supported by the National Natural Science Foundation of China (grant number 31401565), Major projects in key fields of colleges and universities in Guangdong Province (2020ZDZX3027), Major public welfare projects in Zhongshan City (2018B1023 and 2019B2013), and Special innovation projects of Guangdong Universities (2020KTSCX184).

Conflicts of Interest: The authors declare no conflict of interest.

\section{References}

1. Baird-Parker, T.C. The production of microbiologically safe and stable foods. In Microbiological Safety and Quality of Food; Lund, B.M., Baird-Parker, T.C., Gould, G.W., Eds.; Aspen Publishers, Inc.: Gaithersburg, MD, USA, 2000; pp. 3-18. ISBN 978-0-8342-1323-4.

2. Akinola, O.A.; Akinyemi, A.A.; Bolaji, O. Evaluation of traditional and solar fish drying systems towards enhancing fish storage and preservation in Nigeria (Abeokuta local governments as case study). J. Fish. Int. 2006, 1, 44-49.

3. Ghaly, A.E.; Dave, D.; Budge, S.; Brooks, M.S. Fish spoilage mechanisms and preservation techniques: Review. Am. J. Appl. Sci. 2010, 7, 859-877. [CrossRef]

4. Khan, N.; Mukhtar, H. Tea polyphenols for health promotion. Life Sci. 2007, 81, 519-533. [CrossRef]

5. Perumalla, A.V.S.; Hettiarachchy, N.S. Green tea and grape seed extracts-Potential applications in food safety and quality. Food Res. Int. 2011, 44, 827-839. [CrossRef]

6. Fan, W.J.; Chi, Y.L.; Zhang, S. The use of a tea polyphenol dip to extend the shelf life of silver carp (Hypophthalmicthys molitrix) during storage in ice. Food Chem. 2008, 108, 148-153. [CrossRef]

7. Jia, S.L.; Huang, Z.; Lei, Y.T.; Zhang, L.T.; Li, Y.; Luo, Y.K. Application of Illumina-MiSeq high throughput sequencing and culture-dependent techniques for the identification of microbiota of silver carp (Hypophthalmichthys molitrix) treated by tea polyphenols. Food Microbiol. 2018, 76, 52-61. [CrossRef]

8. Li, T.T.; Li, J.R.; Hu, W.Z.; Zhang, X.G.; Li, X.P.; Zhao, J. Shelf-life extension of crucian carp (Carassius auratus) using natural preservatives during chilled storage. Food Chem. 2012, 135, 140-145. [CrossRef]

9. Li, T.T.; Hu, W.Z.; Li, J.R.; Zhang, X.G.; Zhu, J.L.; Li, X.P. Coating effects of tea polyphenol and rosemary extract combined with chitosan on the storage quality of large yellow croaker (Pseudosciaena crocea). Food Control. 2012, 25, 101-106. [CrossRef]

10. Ju, J.; Liao, L.; Qiao, Y.; Xiong, G.Q.; Li, D.S.; Wang, C.; Hu, J.Z.; Wang, L.; Wu, W.J.; Ding, A.Z.; et al. The effects of vacuum package combined with tea polyphenols (V plus TP) treatment on quality enhancement of weever (Micropterus salmoides) stored at $0{ }^{\circ} \mathrm{C}$ and $4{ }^{\circ} \mathrm{C}$. LWT Food Sci. Technol. 2018, 91, 484-490. [CrossRef]

11. Lin, W.L.; Zeng, Q.X.; Zhu, Z.W. Different changes in mastication between crisp grass carp (Ctenopharyngodon idellus C. et V) and grass carp (Ctenopharyngodon idellus) after heating: The relationship between texture and ultrastructure in muscle tissue. Food Res. Int. 2009, 42, 271-278. [CrossRef]

12. Pan, Z.Q.; Li, L.; Shen, Z.H.; Chen, Y.; Li, M. Characterization of the Microbiota in Air- or Vacuum-Packed Crisp Grass Carp (Ctenopharyngodon idella C. et V.) Fillets by 16S rRNA PCR-Denaturing Gradient Gel Electrophoresis and High-Throughput Sequencing. J. Food Prot. 2018, 81, 1022-1029. [CrossRef]

13. Association of Official Analytical Chemists. Standard Methods for the Examination, 17th ed.; Association of Official Analytical Chemists: Washington, DC, USA, 2002.

14. Goulas, A.E.; Kontominas, M.G. Effect of salting and smoking-method on the keeping quality of chub mackerel (Scomber japonicus): Biochemical and sensory attributes. Food Chem. 2005, 93, 511-520. [CrossRef] 
15. The International Commission on Microbiological Specifications for Foods. Sampling plans for fish and shellfish. In Microorganisms in Foods 2, 2nd ed.; Sampling for Microbiological Analysis: Principles and Specific Applications; Blackwell Scientific Publications: London, UK, 1986; ISBN 0-632-01567-5.

16. Li, L.; Pan, Z.Q.; Shen, Z.H. Identification of the dominant microbial species of spoiled crisp grass carp (Ctenopharyngodon idellus C. et V.) and grass carp (Ctenopharyngodon idellus) fillets during cold storage by culture-independent $16 \mathrm{~S}$ rDNA sequence analysis. J. Food Prot. 2018, 81, 84-92. [CrossRef] [PubMed]

17. Olafsdottir, G.; Martinsdottir, E.; Oehlenschlager, J.; Dalgaard, P.; Jensen, B.; Undeland, I.; Mackie, I.M.; Henehan, G.; Nielsen, J.; Nilsen, H. Methods to evaluate fish freshness in research and industry. Trends Food Sci. Technol. 1997, 8, 258-265. [CrossRef]

18. Ruiz-Capillas, C.; Moral, A. Sensory and biochemical aspects of quality of whole bigeye tuna (Thunnus obesus) during bulk storage in controlled atmospheres. Food Chem. 2005, 89, 347-354. [CrossRef]

19. Ojagh, S.M.; Rezaei, M.; Razavi, S.H.; Hosseini, S.M.H. Effect of chitosan coatings enriched with cinnamon oil on the quality of refrigerated rainbow trout. Food Chem. 2010, 120, 193-198. [CrossRef]

20. Wang, H.; Luo, Y.K.; Huang, H.P.; Xu, Q. Microbial succession of grass carp (Ctenopharyngodon idellus) filets during storage at $4{ }^{\circ} \mathrm{C}$ and its contribution to biogenic amines' formation. Int. J. Food Microbiol. 2014, 190, 66-71. [CrossRef]

21. Zhang, Y.M.; Li, Q.; Li, D.P.; Liu, X.C.; Luo, Y.K. Changes in the microbial communities of air-packaged and vacuum-packaged common carp (Cyprinus carpio) stored at $4{ }^{\circ} \mathrm{C}$. Food Microbiol. 2015, 52, 197-204. [CrossRef]

22. Gram, L.; Huss, H.H. Microbiological spoilage of fish and fish products. Int. J. Food Microbiol. 1996, 33, 121-137. [CrossRef]

23. Gonzalez, C.J.; Santos, J.A.; Garcia-Lopez, M.L.; Gonzalez, N.; Otero, A. Mesophilic aeromonads in wild and aquacultured freshwater fish. J. Food Prot. 2001, 64, 687-691. [CrossRef] [PubMed]

24. Gui, M.; Song, J.; Zhang, Z.; Hui, P.; Li, P. Biogenic amines formation, nucleotide degradation and TVB-N accumulation of vacuum-packed minced sturgeon (Acipenser schrencki) stored at $4{ }^{\circ} \mathrm{C}$ and their relation to microbiological attributes. J. Sci. Food Agric. 2014, 94, 2057-2063. [CrossRef] [PubMed] 